\title{
A negociação de faces, teritónios e lugares em uma perspectiva interacionista da análise do discurso
}

The negotiation of faces, territories and places in an interactive perspective of discourse analysis

Gustavo Ximenes Cunha Universidade Federal de Minas Gerais (UFMG), Belo Horizonte, MG, Brasil Rafael Vinícius de Carvalho Picinin Universidade Federal de Minas Gerais (UFMG), Belo Horizonte, MG, Brasil

Resumo: Este trabalho tem por finalidade apresentar o Modelo de Análise Modular do Discurso, evidenciando que seus instrumentos teóricos e metodológicos permitem um estudo aprofundando não apenas da estruturação de discursos dialogais, mas também de processos complexos de negociação de faces, territórios e lugares característicos de gêneros monologais. Ao final do percurso de análise de uma cartilha institucional da ANATEL, verificou-se o papel que a cadeia referencial da cartilha desempenha na gestão das relações de faces, territórios e lugares, bem como a forte interação entre aspectos ligados à seleção de recursos linguísticos e textuais e aspectos de ordem situacional.

Palavras-chave: Modelo de Análise Modular do Discurso. Estratégia discursiva. Cartilha.

Abstract: This paper presents the Modular Approach to Discourse Analysis and shows that its theoretical and methodological tools allow a study not only of the structure of dialogic discourses, but also of complex processes of negotiation of faces, territories and places of monological genres. At the end of the analysis of an institutional booklet of ANATEL, we verified the role of its reference chain in the management of relations of faces, territories and places, as well as the strong connection between the selection of linguistic and textual resources and contextual aspects.

Key-words: Modular Approach to Discourse Analysis. Discursive strategy. Booklet.

\section{Introdução}

Nas últimas décadas, os estudos do texto e do discurso têm se caracterizado pela percepção de que a linguagem não constitui nem um produto cuja complexidade se resolve na descrição de sua estrutura, nem um processo cuja 
responsabilidade recai apenas sobre o produtor do discurso. Atualmente, os estudos do texto e do discurso, sob o influxo, em especial, de abordagens enunciativas, como as de Benveniste, Bakhtin e Voloshinov, bem como de abordagens microssociológicas, como as de Goffman e Gumperz, e da Análise da Conversação, de Sacks e Schegloff, colocam a interação no centro da Gustavo análise e entendem que todo processo de constituição de sentidos por meio Ximenes Cunha

Rafael Vinícius de Carvalho da linguagem (oral ou escrita) é o resultado da colaboração de, pelo menos, dois interlocutores (VION, 1992, KERBRAT-ORECCHIONI, 1992, KOCH, 1997, BENTES; REZENDE, 2008).

Embora as abordagens que podem ser amplamente caracteriza-

Picinin das como interacionistas não formem um campo homogêneo no interior dos estudos da linguagem, dada a diversidade de princípios e posicionamentos teóricos e de procedimentos metodológicos, observa-se que todas compartilham alguns postulados gerais, postulados que permitem distingui-las, de um lado, de abordagens mais voltadas para o estudo da língua enquanto sistema fechado em si e, de outro, de abordagens mais radicalmente cognitivistas e, por isso, centradas no produtor do discurso (VION, 1992, KERBRAT-ORECCHIONI, 1992, ROULET; FILLIETTAZ; GROBET, 2001, MORATO, 2004). Esses postulados são:

- a comunicação não corresponde a uma simples transmissão de informações entre sujeitos desvinculados do contexto histórico e social;

- todo enunciado, mesmo que superficialmente seja monologal (produzido por um único locutor), é dialogal, uma vez que todo enunciado é uma resposta a enunciados prévios e é endereçado a um outro;

- todo processo de comunicação implica uma determinação recíproca das ações linguageiras e não-linguageiras realizadas pelos interlocutores;

- tanto quanto o locutor, o interlocutor deve ser considerado como um participante ativo da interação, na medida em que realiza não só uma atividade cognitiva de processamento de informações, mas também uma atividade reguladora dos comportamentos realizados na interação;

- o conjunto das regras linguísticas pré-existentes às interações apresenta uma estabilidade relativa, já que essas regras são fluidas, variáveis e dependentes do contexto, sendo a língua parcialmente constituída no curso da interação. 
Inserido nessa vertente dos estudos interacionistas, este trabalho tem por objetivo apresentar um modelo de Análise do Discurso ao qual subjazem esses postulados, o Modelo de Análise Modular do Discurso. Definindo-se como uma abordagem cognitivo-interacionista, o modelo, como veremos mais detalhadamente adiante, busca integrar, numa mesma perspectiva de análise, as dimensões linguística, textual e situacional do discurso. Isso significa que, para essa abordagem, uma compreensão global da organização do discurso somente se alcança mediante a articulação equilibrada de informações relativas às estruturas propriamente linguísticas, aos processos de construção do texto e à situação (o contexto) de que a interação é parte constitutiva (ROULET; FILLIETTAZ; GROBET, 2001).

Neste trabalho, a apresentação de instrumentos teóricos e proA negociação de faces, territóriose lugares em uma perspectiva interacionista da análise do discurso cedimentos metodológicos do modelo modular será feita com base na análise de um exemplar de um gênero monologal e escrito: uma cartilha institucional. Filiando-se a um projeto de pesquisa mais amplo ${ }^{1}$, o presente trabalho busca mostrar que, embora tradicionalmente as abordagens interacionistas se dediquem, sobretudo, ao estudo de gêneros dialogais e orais, os processos interacionais de co-construção de sentidos, de negociação de imagens identitárias e de constituição de posições sociais estão igualmente presentes na interação mediada por discurso monologal e escrito. Nesse sentido, este trabalho evidencia que o estudo de discursos monologais pode se beneficiar do emprego dos instrumentos teóricos e metodológicos desenvolvidos pelas abordagens interacionistas, para as quais, como exposto em um dos postulados acima, todo enunciado, mesmo que monologal, é essencialmente dialogal, por ser sempre uma resposta a enunciados prévios e endereçado a um outro. Assim, após uma apresentação dos princípios gerais que definem o Modelo de Análise Modular do Discurso, procederemos ao estudo de uma cartilha institucional produzida pela Agência Nacional de Telecomunicações (ANATEL). Nesse estudo, mostraremos o papel que a construção da cadeia referencial do discurso exerce na negociação de faces, territórios e lugares.

1 Este trabalho filia-se ao projeto de pesquisa intitulado "A negociação de imagens identitárias no discurso organizacional", coordenado pelo Professor Gustavo Ximenes Cunha, na Faculdade de Letras, da UFMG. Esse projeto tem por objetivo estudar, à luz do Modelo de Análise Modular do Discurso, as estratégias discursivas empregadas na gestão das relações de faces, territórios e lugares em dez cartilhas produzidas por cinco agências reguladoras do Estado (ANAC, ANP, ANATEL, ANTT, ANVISA). 


\section{Modelo de Análise Modular do Discurso: um modelo para o estudo da organização do discurso}

Tendo como finalidade propor um instrumento de análise para o estudo da complexidade da organização do discurso e superar abordagens teóricas que se ocupam de aspectos parciais dessa organização, o Modelo Gustavo de Análise Modular do Discurso, desenvolvido na Universidade de GeneXimenes Cunha

Rafael Vinícius de Carvalho bra por equipe liderada por Eddy Roulet, oferece bases teóricas e metodológicas capazes de integrar e consolidar variadas pesquisas contemporâneas orientadas à compreensão e à análise do discurso (ROULET,

Picinin 1999, ROULET; FILLIETTAZ; GROBET, 2001). Assim, o modelo modular busca integrar, em um mesmo arcabouço teórico e metodológico, abordagens que se centraram em diferentes dimensões (linguísticas, textuais e situacionais) da organização discursiva. Como exposto em Cunha (2016, p. 33-34),

Do ponto de vista teórico, o fato de o modelo modular se inserir na corrente interacionista dos estudos da linguagem dá a ele especificidades que o diferenciam de outras abordagens do campo da Análise do Discurso. Ao se definir como um modelo interacionista, o modelo modular busca contribuições da Análise da Conversação de orientação etnometodológica (SACKS; SCHEGLOFF; JEFFERSON, 2003[1974]), da Pragmática (GRICE, 1979, AUSTIN, 1962; BROWN; LEVINSON, 1983), da Sociolinguística (LABOV; FANSHEL, 1977), da Microssociologia (GOFFMAN, 2011). (...) Entretanto, a filiação do modelo a essa mesma corrente de estudos não impede que seus pesquisadores considerem que as práticas discursivas são reguladas por expectativas sociais e históricas, as quais fazem com que os estudos focados apenas ou principalmente nos processos emergentes de estruturação da conversação precisem ser reconsiderados num quadro teórico mais amplo (BURGER, 1997).

Porque assume uma perspectiva interacionista ampliada e não focada exclusivamente nos processos de estruturação da conversa, o modelo modular incorpora contribuições de Bakhtin (2003), como a noção de dialogismo, e considera que "todo discurso é sempre uma resposta a discursos previamente produzidos e é elaborado em vista de um interlocutor efetivo ou potencial" (CUNHA, 2016, p. 34). Essa perspectiva permite ao modelo expandir seu horizonte de investigação, estudando não apenas interações face a face, mas também interações caracteriza- 
das pela distância espacial e temporal entre os interlocutores, como é o caso da cartilha estudada neste trabalho.

Por meio dessa abordagem de cunho interacionista, o modelo genebrino permite articular as dimensões linguística (ligada à sintaxe, ao léxico e às variedades linguísticas), textual (relacionada à estrutura hierárquica do texto) e situacional (atinente ao universo de referência e à situação de interação) que constituem o discurso (ROULET; FILLIETTAZ; GROBET, 2001). Ao incorporar ao estudo da organização do discurso uma dimensão textual, o modelo propõe uma distinção precisa entre as noções de texto e de discurso. No modelo, o texto diz respeito à maneira como os constituintes textuais (trocas, intervenções e atos) se organizam hierarquicamente, ao passo que o discurso corresponde à articulação das dimensões linguística, textual e situacional. Nessa maneira de conceber A negociação de faces, territóriose lugares em uma perspectiva interacionista da análise do discurso a relação entre texto e discurso, o texto corresponde a uma dimensão particular do discurso e, por isso, pode ser estudado em um módulo específico, o hierárquico (ROULET; FILLIETTAZ; GROBET, 2001, CUNHA, 2014).

A metodologia modular adotada pelo modelo favorece, assim, a compreensão da complexidade do discurso por meio de módulos recursivamente combinados. Tendo em vista a adoção pelo modelo dessa metodologia modular de análise, torna-se imprescindível a compreensão da noção de módulo, que se concebe como "um sistema de informações elementares, o qual deve fornecer a descrição de um domínio específico da organização discursiva" (CUNHA, 2014, p. 30). Nessa perspectiva, cada dimensão do discurso (linguística, textual ou situacional) é composta por módulos. Totalizam-se, com efeito, cinco módulos, que definem as informações que podem ser independentemente descritas. A dimensão linguística decompõe-se nos módulos lexical e sintático. A dimensão textual é formada pelo módulo hierárquico. Por fim, a dimensão situacional decompõe-se nos módulos interacional e referencial.

Na produção e compreensão do discurso, as informações modulares combinam-se em formas de organização elementares e complexas. No modelo, propõem-se sete formas de organização elementares: fono-prosódica ou gráfica, semântica, relacional, informacional, enunciativa, sequencial e operacional. Essas formas de organização são chamadas de elementares, porque resultam da combinação de informações extraídas apenas dos módulos. No modelo, são propostas outras cinco formas de organização, as complexas: periódica, tópica, polifônica, composicional e estratégica. Essas formas de organização são chamadas de comple- 
xas porque resultam da combinação de informações extraídas do estudo dos módulos e de formas de organização elementares e/ou complexas (ROULET; FILLIETTAZ; GROBET, 2001, MARINHO, 2004).

Em síntese, o Modelo de Análise Modular do Discurso propõe a compreensão do discurso, de modo a explicitar as informações e os eleGustavo mentos básicos que o integram, permitindo, pois, a construção de um Ximenes Cunha

Rafael Vinícius diálogo articulado entre diversas teorias e abordagens dedicadas aos estudos discursivos. Além disso, a metodologia modular proposta pelo de Carvalho modelo apresenta uma natureza bastante flexível, permitindo ao estudioso definir o percurso de análise que considere o mais adequado, em função de seus objetivos de pesquisa, bem como do corpus de análise.

Assim, para dar conta do papel que a cadeia referencial da cartilha da ANATEL exerce na negociação de faces, territórios e lugares entre suas instâncias de produção e recepção, nossa análise será realizada em algumas etapas. Inicialmente, analisaremos a cartilha do ponto de vista do módulo referencial, cujo estudo permitirá compreender essa cartilha como um exemplar de um gênero oficial utilizado por uma agência reguladora do Estado, bem como a natureza da interação entre a instância que se responsabiliza pela cartilha, a agência, e o leitor. Estudado o contexto de produção da cartilha, descreveremos sua forma de organização informacional, investigando os procedimentos de (re) ativação de objetos de discurso empregados na construção da cadeia referencial da cartilha. Em seguida, procederemos ao estudo da forma de organização tópica da cartilha, a fim de explicar, por meio da estrutura do texto, fenômenos identificados no estudo da organização informacional. Por fim, estudaremos a forma de organização estratégica da cartilha, combinando o estudo do módulo referencial e o estudo das formas de organização informacional e tópica. O objetivo dessa etapa final do trabalho é explicar em que medida as propriedades da cadeia referencial da cartilha refletem a negociação de faces, territórios e lugares entre a agência reguladora, instância responsável pela produção da cartilha, e o leitor ${ }^{2}$.

2 Em Cunha (2016), foi proposta uma análise de uma cartilha da Agência Nacional do Petróleo, Gás Natural e Biocombustíveis (ANP), com base no Modelo de Análise Modular do Discurso. Em função das especificidades da organização dessa cartilha e da flexibilidade da metodologia do modelo modular, foi adotado um percurso de análise diferente do que ora propomos para a cartilha da ANATEL. No estudo da cartilha da ANP, partiu-se da análise do módulo referencial. No interior da forma de organização estratégica, os resultados do módulo referencial foram sendo paulatinamente combinados com os resultados dos módulos sintático e hierárquico e das formas de organização sequencial, informacional e composicional. 


\section{Análise da cartilha à luz do módulo referencial}

Integrante da dimensão situacional do discurso, o módulo referencial estuda as relações que o discurso mantém com o mundo em que é produzido, assim como as relações que mantém com o mundo que representa. Por adotar uma perspectiva interacionista dos estudos da linguagem, o modelo modular entende como o mundo em que o discurso se insere as relações interpessoais que se estabelecem entre os interlocutores, bem como o feixe de traços sociais (status social, face, território etc) que caracterizam as posições assumidas pelos agentes na interação. Quanto ao mundo que o discurso representa, o modelo modular considera que o mundo representado no discurso é construído em função do mundo em que o discurso se insere. Assim, o mesmo fato (um assalto, por exemplo) será narrado diferentemente por um jornalista, por uma testemunha e por um policial, exatamente porque esses agentes assumem posições divergentes na interação.

Para Rufino (2006), o módulo referencial tem categorias capazes de descrever as atividades, as ações e os conceitos envolvidos em uma determinada interação, a saber: representações praxiológicas e conceituais (esquemáticas e subjacentes ao discurso), estruturas praxiológicas e conceituais (emergentes e ligadas a realidades particulares), bem como o quadro acional, que trata da relação estabelecida pelos interlocutores e mediada seja por discurso oral, seja por discurso escrito. Desses instrumentos de análise, consideramos que dois deles são particularmente pertinentes para a compreensão do contexto de produção da cartilha da ANATEL: a representação conceitual e o quadro acional.

A representação conceitual tem por finalidade inventariar as propriedades típicas que podem ser atribuídas a um conceito ou referente. No módulo referencial, considera-se que os agentes dispõem de conhecimentos esquemáticos acerca dos objetos, seres e noções, conhecimentos que são mobilizados em uma interação (FILLIETTAZ, 2000). A representação conceitual explicita esses conhecimentos esquemáticos, que se distinguem por um forte grau de tipicalidade ou tipicidade (CUNHA, 2008).

No que se refere às cartilhas produzidas por agências reguladoras do Estado (e não apenas à cartilha produzida pela ANATEL), a representação conceitual do mundo em que elas se inserem pode ser compor de algumas propriedades características, tais como sua instância de produção e o governo ao qual essa instância está ligada. No Brasil, as agências reguladoras foram criadas no governo Fernando Henrique Cardoso (FHC), no contexto da Reforma do Estado. Com as privatizações empreendidas no 
âmbito dessa reforma, a finalidade do então governo era fazer com que o Estado deixasse o lugar de protagonista na execução dos serviços sociais e passasse a exercer funções de planejamento, regulação e fiscalização e a ser essencialmente um promotor da competitividade econômica (BRESSER-PEREIRA, 1997). Criadas nesse contexto, as agências são instituições

Gustavo

Ximenes Cunha

Rafael Vinícius

de Carvalho

Picinin que detêm o poder de formular regras e disciplinar a atuação dos agentes econômicos e cuja função central é regular serviços públicos delegados a empresas privadas (BARROSO, 2002, DASSO Jr., 2006).

Quanto ao papel que o discurso exerce no funcionamento das agências, asseveram Cunha, Oliveira e Picinin (2017, p. 5):

O funcionamento das agências está profundamente atrelado à realização de atividades discursivas, ou seja, ao uso intensivo da linguagem. Isso porque, para exercerem esse papel de órgão regulador e interventor, as agências se valem de uma profusão de gêneros do discurso, sobretudo escritos, por meio dos quais elas dialogam com os agentes econômicos e com os diferentes segmentos da sociedade diretamente afetados pela atuação desses agentes.

Desse modo, o exame de cartilhas institucionais revela que, por meio delas, as agências exercem basicamente duas ações: "(i) regular o comportamento de segmentos sociais, ditando seus deveres, e (ii) determinar como deve ser o papel desses segmentos no trato com as empresas privadas, ditando seus direitos" (CUNHA; OLIVEIRA; PICININ, 2017, p. 6). Assim, do ponto de vista do mundo em que as cartilhas se inserem, verifica-se que o referente cartilha constitui um conceito derivado do referente Agências Reguladoras. Este conceito, por sua vez, é derivado diretamente dos conceitos Governo FHC e Reforma do Estado. A figura 1 busca representar essas relações de derivação entre conceitos.

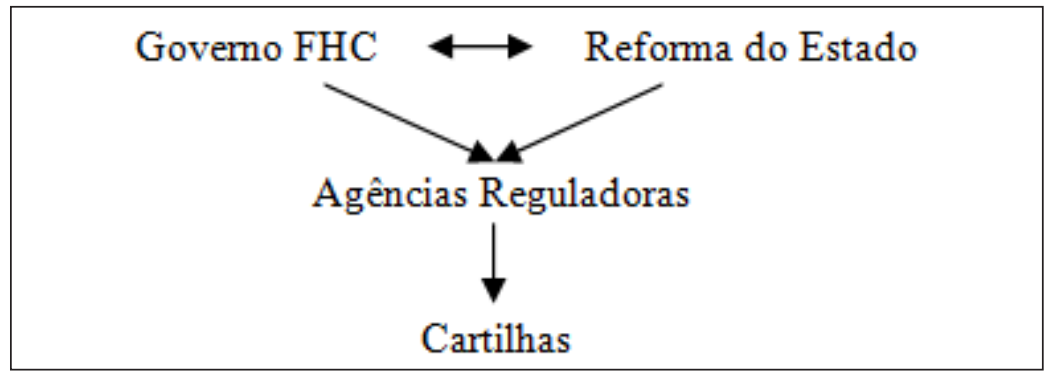

Figura 1 - Representação conceitual 
Feita a descrição da representação conceitual da cartilha, podemos tratar da cartilha produzida pela ANATEL, por meio da descrição de seu quadro acional. $\mathrm{O}$ quadro acional é um instrumento de análise com que se descrevem as propriedades referenciais de uma interação efetiva, propriedades que dizem respeito aos agentes e ao modo como participam da interação. No quadro acional, a descrição das propriedades de uma situação específica resulta da articulação de quatro parâmetros: os enjeux comuns, as ações participativas, os complexos motivacionais e as posições acionais.

Os enjeux comuns correspondem à finalidade compartilhada pelos interlocutores. As ações participativas referem-se às "parcelas interdependentes de responsabilidade que cabem a cada um dos interactantes na emergência de um 'enjeu comum”' (ROULET; FILLIETTAZ; GROBET, 2001, p. 114). Os complexos motivacionais definem às razões exteriores à situaA negociação de faces, territóriose lugares em uma perspectiva interacionista da análise do discurso ção de discurso que levam os interlocutores a interagir. Por fim, as posições acionais descrevem as identidades que são efetivamente assumidas pelos agentes. No modelo modular, a identidade que um locutor assume é o resultado da articulação de diferentes noções. Assim, para se chegar à posição acional dos participantes da interação, consideram-se o status social de cada um deles, os papéis praxiológicos ligados às ações participativas, às faces e aos territórios em jogo ${ }^{3}$. Com o quadro acional, o módulo referencial oferece um instrumento de análise flexível o suficiente para descrever as particularidades de interações efetivas e capaz de explicitar a forma como os agentes estruturam sua associação momentânea (ROULET; FILLIETTAZ; GROBET, 2001, CUNHA, 2016).

Em relação à cartilha em análise, considerando o contexto da Reforma de Estado e da privatização das empresas públicas de telecomunicações, verificamos que a ANATEL é o locutor que se responsabiliza pela cartilha e cujo propósito é explicitar ao usuário dos serviços de telefonia fixa quais são seus direitos e deveres no trato com as empresas privadas prestadoras desses serviços, bem como os deveres dessas empresas, relativamente à contratação e à prestação dos serviços ${ }^{4}$. Nesse

3 Relativamente à noção de face, ela deve ser compreendida como "valor social postivo que uma pessoa efetivamente reivindica para si mesma através da linha [de conduta social] que os outros pressupõem que ela assumiu durante um contato particular" (GOFFMAN, 2011, p. 13-14). Complementando a definição goffmaniana de face, a noção de território pode ser compreendida como o conjunto de elementos físicos e simbólicos preservados pelo locutor no decorrer da interação (GOFFMAN, 1973).

4 Seguindo a perspectiva enunciativa de Ducrot (1987), entendemos como o locutor a instância que assume a responsabilidade pelo que é dito/escrito e não o sujeito empírico que produz o enunciado. Por isso, o locutor da cartilha é a ANATEL e não seu redator anônimo, já que toda a responsabilidade pelas informações nela expressas é da agência. Para mais detalhes sobre o regime enunciativo de discursos oficiais, cf. Cunha (2016a). 
sentido, constitui o enjeu da cartilha ou sua finalidade a orientação/instrução do leitor quanto a direitos e deveres, o que se expressa já na capa da cartilha (figura 2), onde se faz menção aos direitos do consumidor dos serviços de telefonia5:

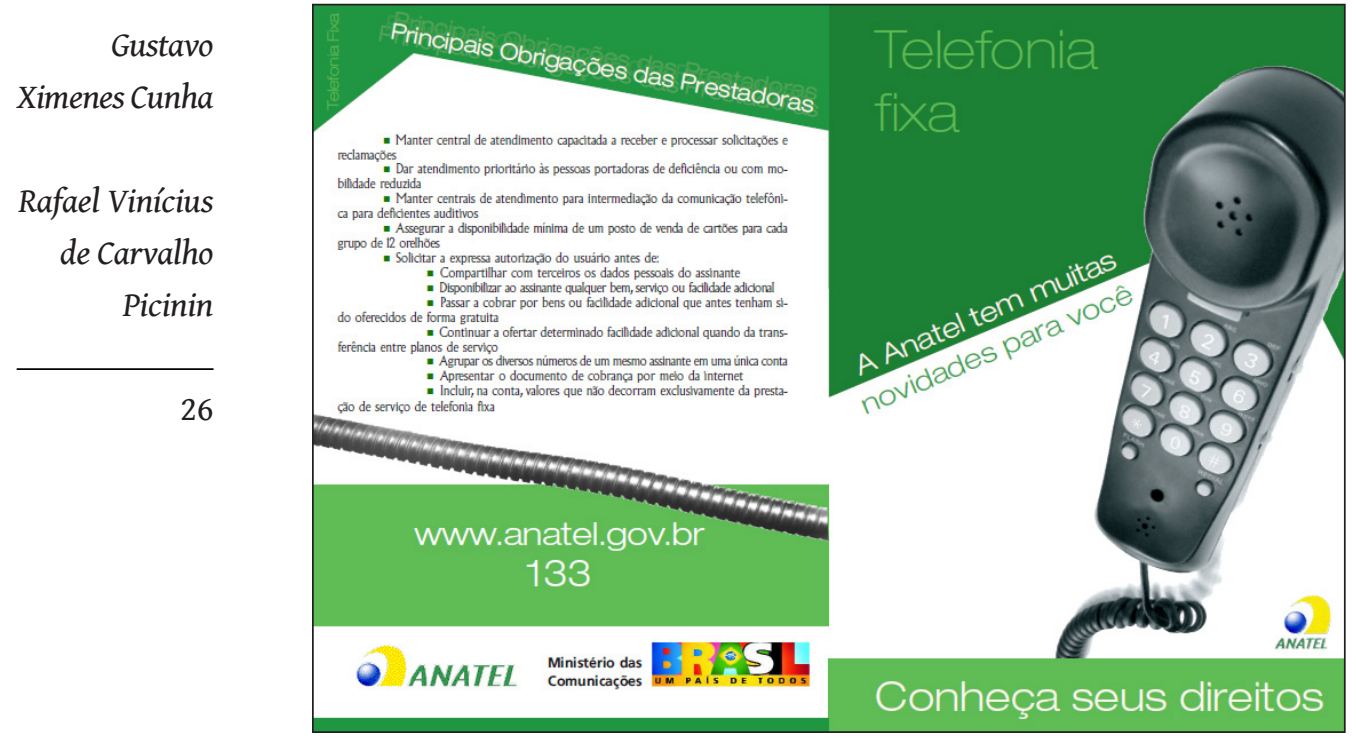

Figura 2 - Cartilha da ANATEL

Do ponto de vista das ações participativas, ao informar o usuário sobre seus direitos e sobre os deveres das empresas em sede da contratação e prestação de serviços de telefonia fixa, a ANATEL, por meio da cartilha, exerce as funções de planejamento, regulação e fiscalização, as quais foram assumidas pelo Estado ao deixar de executar diretamente os serviços públicos de telefonia, após as privatizações. Nas quatro páginas de que a cartilha se compõe, a ANATEL expressa os direitos do consumidor em trechos como estes:

\footnotetext{
Principais Direitos dos Usuários

Na sua relação com a prestadora:

Conhecer previamente as condições de contratação, prestação e suspensão do serviço

Receber cópia do contrato de prestação de serviço, gratuita-
}

5 A cartilha completa pode ser acessada em: < http://www.anatel.gov.br/Portal/verificaDocumentos/ documento.asp?numeroPublicacao=325142\&filtro=1\&documentoPath=325142.pdf>. Acesso: 20 mar. 2016. 
mente e independente de solicitação

Mudar de plano de serviço, sem estabelecimento de prazo de vínculo (fidelização ou carência)

E a agência expressa os deveres das empresas em trechos como estes:

Principais Obrigações das Prestadoras

Manter central de atendimento capacitada a receber e processar solicitações e reclamações

Dar atendimento prioritário às pessoas portadoras de deficiência ou com mobilidade reduzida

Manter centrais de atendimento para intermediação da comunicação telefônica para deficientes auditivos

A negociação

de faces,

territóriose

lugares em uma

perspectiva

interacionista

da análise do

discurso

Relativamente às posições acionais, o status social dos interlocutores é estável durante toda a interação, uma vez que a ANATEL assume, de fato, o papel de agência reguladora, ao passo que o leitor com quem a agência dialoga por meio da cartilha assume o status social de consumidor dos serviços de telefonia fixa prestados por empresas privadas. No tocante aos papéis praxiológicos, verifica-se que a agência assume papel de informadora, ordenadora e controladora, de modo a construir/preservar a face de defensora dos direitos do consumidor, adentrando, consequentemente, no território do usuário para esclarecer a ele quais direitos poderão ser facultativamente exercidos por si na relação de consumo. As informações do quadro acional podem ser esquematizadas na figura 3.

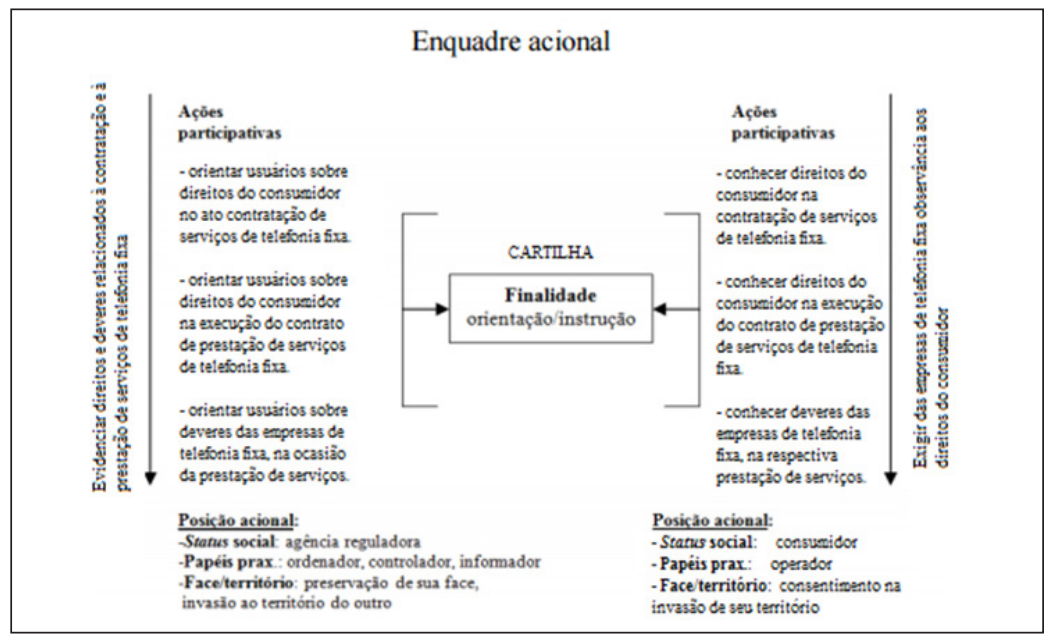

Figura 3 - Quadro acional 
$\mathrm{Na}$ última etapa do estudo (a forma de organização estratégica), as informações obtidas com a descrição da representação conceitual e do quadro acional da cartilha da ANATEL serão combinadas com as informações resultantes do estudo das formas de organização informacional e tópica.

Gustavo

Ximenes Cunha

Rafael Vinícius

\section{Análise da forma de organização informacional da cartilha}

Neste item, realizamos o estudo da forma de organização informacional de Carvalho da cartilha da ANATEL. Essa forma de organização resulta da combina-

Picinin ção de informações dos módulos hierárquico, referencial, lexical e sintático e tem como finalidade estudar a cadeia referencial do discurso, descrevendo a continuidade, o encadeamento e a progressão das informações contidas em cada ato ${ }^{6}$ (GROBET, 2000, CUNHA, 2008, 2013, 2014).

Conforme Grobet (2000), cada ato componente de uma produção discursiva ativa uma informação que pode ter pontos de ancoragem situados em níveis diferentes da memória discursiva dos interlocutores (conhecimentos compartilhados). 0 ponto de ancoragem mais imediatemente acessível na memória discursiva é o tópico. A título de ilustração, consideremos os atos (03-04) da cartilha da ANATEL:

(03) A Anatel tem muitas novidades para você

(04) Conheça seus direitos

O ato (03) ativa a informação você. Uma vez estocada na memória discursiva dos interactantes, essa informação constitui o tópico do ato (04), já que essa é a informação mais diretamente acessível em que o ato (04) se liga. Nas produções discursivas, os tópicos podem ser verbalizados por traços tópicos, como pronomes e expressões nominais definidas. No ato (04) do exemplo acima, o pronome seus constitui o traço que indica a ancoragem desse ato no tópico constituído por informação (você) previamente ativada em (03).

No modelo, considera-se ainda que cada ato pode se encadear ao tópico por meio de três formas de encadeamento ou tipos de progressão: progressão linear (o tópico do ato tem origem na informação imediatamente precedente), progressão com tópico constante (uma su-

$6 \quad$ O ato é a unidade mínima de análise do modelo modular e constitui uma das categorias definidas no módulo hierárquico (ROULET; FILLIETTAZ; GROBET, 2001). 
cessão de atos se ancora no mesmo tópico), e encadeamento à distância (o tópico do ato tem origem em informação mais distante) (ROULET; FILLIETTAZ: GROBET, 2001). No exemplo acima, o ato (04) se liga ao tópico por progressão linear, uma vez que o tópico de (04) é informação ativada no ato imediatamente anterior.

No estudo da forma de organização informacional da cartilha da ANATEL, analisamos a sucessão dos 73 atos componentes do discurso, de modo a identificar o tópico em que a informação ativada em cada ato se ancora, bem como o modo de encadeamento do ato ao tópico. Por motivo de espaço, ilustraremos o estudo da forma de organização informacional por meio de um fragmento da cartilha. 0 quadro 1 apresenta a estrutura informacional do fragmento selecionado, que é o resultado da análise da forma de organização informacional ${ }^{7}$.

A negociação
de faces,
territóriose
lugares em uma
perspectiva
interacionista
da análise do
discurso

\begin{tabular}{|l|l|l|}
\hline$(05)$ & Principais Direitos dos Usuários [você] & $\begin{array}{l}\text { Encadeamento } \\
\text { à distância }\end{array}$ \\
\hline$(06)$ & Na sua [você] relação com a prestadora: & $\begin{array}{l}\text { Tópico } \\
\text { constante }\end{array}$ \\
\hline$(07)$ & $\begin{array}{l}\text { (Direitos dos Usuários) Conhecer previamente as condições de } \\
\text { contratação, prestação e suspensão do serviço }\end{array}$ & $\begin{array}{l}\text { Encadeamento } \\
\text { à distância }\end{array}$ \\
\hline$(08)$ & $\begin{array}{l}\text { (Direitos dos Usuários) Receber cópia do contrato de prestação } \\
\text { de serviço, gratuitamente e independente de solicitação }\end{array}$ & $\begin{array}{l}\text { Tópico } \\
\text { constante }\end{array}$ \\
\hline$(09)$ & $\begin{array}{l}\text { (Direitos dos Usuários) Mudar de plano de serviço, sem estabe- } \\
\text { lecimento de prazo de vínculo }\end{array}$ & $\begin{array}{l}\text { Tópico } \\
\text { constante }\end{array}$ \\
\hline$(10)$ & (prazo de vínculo) (fidelização ou carência) & $\begin{array}{l}\text { Progressão } \\
\text { linear }\end{array}$ \\
\hline$(11)$ & $\begin{array}{l}\text { (Direitos dos Usuários) Cancelar, a qualquer momento, o plano } \\
\text { de serviço escolhido }\end{array}$ & $\begin{array}{l}\text { Encadeamento } \\
\text { à distância }\end{array}$ \\
\hline$(12)$ & $\begin{array}{l}\text { (Direitos dos Usuários) Ao trocar de prestadora, } \\
\text { Tópico } \\
\text { constante }\end{array}$ \\
\hline$(13)$ & $\begin{array}{l}\text { (Direitos dos Usuários) ter a divulgação do seu novo número } \\
\text { nas chamadas destinadas ao número antigo }\end{array}$ & $\begin{array}{l}\text { Tópico } \\
\text { constante }\end{array}$ \\
\hline$(14)$ & $\begin{array}{l}\text { (Direitos dos Usuários) Não pagar a assinatura referente ao } \\
\text { período de suspensão total do serviço por falta de pagamento }\end{array}$ & $\begin{array}{l}\text { Tópico cons- } \\
\text { tante }\end{array}$ \\
\hline$(15)$ & $\begin{array}{l}\text { (Direitos dos Usuários) Não ser cobrado por nenhum serviço, } \\
\text { bem ou facilidade adicional }\end{array}$ & $\begin{array}{l}\text { Tópico } \\
\text { constante }\end{array}$ \\
\hline$(16)$ & $\begin{array}{l}\text { (serviço ou facilidade adicional) (por exemplo, secretária } \\
\text { eletrônica, identificador de chamadas, siga-me) }\end{array}$ & $\begin{array}{l}\text { Progressão } \\
\text { linear }\end{array}$ \\
\hline$(17)$ & (Não ser cobrado) após 24 horas do pedido de cancelamento & $\begin{array}{l}\text { Encadeamento } \\
\text { à distância }\end{array}$ \\
\hline
\end{tabular}

\section{Quadro 1 - Estrutura informacional}

7 Conforme as convenções de apresentação da análise da organização informacional, no quadro, os atos são numerados, e os traços que remetem ao tópico são apresentados em negrito. 0 tópico aparece entre colchetes, depois do traço. Quando o tópico não é verbalizado por traço tópico, ele aparece entre parênteses, no início do ato. 
Nesse trecho, a maior parte dos atos $(06,08,09,12-15)$ liga-se ao mesmo tópico, já que a maior parte deles trata dos Direitos dos Usuários. Por isso, o trecho caracteriza-se pela predominância da progressão por tópico constante. $\mathrm{O}$ ato (5) liga-se ao tópico por encadeamento à distância, porque se ancora em informação ativada em (3), usuário ou Gustavo você. Nesse ato ((3) A Anatel tem muitas novidades para você), a instância de Ximenes Cunha

Rafael Vinícius produção da cartilha faz referência direta ao leitor. Os atos (10) e (16) ligam-se ao tópico por progressão linear, uma vez que se encadeiam em de Carvalho informação ativada no ato imediatamente anterior. Os atos (7) e (11) Picinin ligam-se ao tópico por encadeamento à distância, pois remetem a uma informação ativada em (5), que diz respeito aos direitos dos usuários. 0 ato (17) também liga-se ao tópico por encadeamento à distância, por se encadear em informação ativada em (15), a qual se refere à vedação de cobrança pela prestação de serviços adicionais de telefonia fixa.

Vale chamar a atenção para a forma como, ao longo trecho, ao referente você, ativado inicialmente no ato (03), vão sendo atribuídas as propriedades não de um cidadão com direitos e deveres prescritos, por exemplo, na Constituição, mas de um usuário ou um consumidor de serviços com direitos e deveres contratuais, o que constitui um reflexo do status social de consumidor assumido pelo leitor da cartilha, tal como apontado no quadro acional (figura 3). Assim, esse interlocutor com quem a agência (o Estado) dialoga é alguém que deve estar atento a contratos (07 - Conhecer previamente as condições de contratação, prestação e suspensão do serviço), que tem liberdade para mudar de empresa (09 - Mudar de plano de serviço, sem estabelecimento de prazo de vínculo) e que não deve se deixar enganar pela atuação de empresas (15 - Não ser cobrado por nenhum serviço, bem ou facilidade adicional). Desse modo, porque a ANATEL dialoga com um consumidor, o leitor, ao longo de toda a cartilha, é referido cinco vezes como usuário, uma vez como consumidor e nenhuma como cidadão. Mais adiante, veremos as implicações que a construção do referente você como consumidor tem para a gestão de relações de faces, territórios e lugares.

Com a análise dos 73 atos que integram o discurso completo da cartilha, verificou-se que nela há 19 (26,38\%) progressões lineares, 26 $(36,11 \%)$ encadeamentos à distância e $27(37,5 \%)$ tópicos constantes. A menor percentagem dos atos se liga ao tópico por meio de progressão linear, sendo expressiva a quantidade de atos relacionados ao tópico por tópico constante e encadeamento à distância. 
Além disso, $45(61,64 \%)$ atos não apresentam traços tópicos, ou seja, não trazem itens anafóricos que remetem ao tópico, enquanto apenas $28(38,36 \%)$ atos apresentam traços tópicos. Sendo assim, a maior parte do discurso não possui marca linguística indicativa de qual é o tópico de um ato. Porém, apesar de a maior parte dos atos não apresentar traços tópicos, os tópicos podem ser facilmente recuperados na memória discursiva, porque toda a cartilha aborda fundamentalmente o tema de direitos dos usuários quanto à prestação de serviços de telefonia fixa.

Feitas essas considerações, passaremos à análise da forma de organização tópica da cartilha, por meio da combinação do estudo da forma de organizacão informacional, realizada neste item, e do estudo do módulo hierárquico. Como veremos, a forma de organização tópica tem por finalidade dinamizar a descrição da cadeia referencial propiciada pela forma de organização informacional.

\section{Análise da forma de organização tópica da cartilha}

$\mathrm{Na}$ análise da forma de organização tópica, procura-se dinamizar a análise da forma de organização informacional, descrevendo, em especial, a hierarquia e as relações de derivação entre as informações ativadas em um discurso, com o fim de explicar os encadeamentos verificados na descrição da estrutura informacional. Para explicar os processos que subjazem a esses encadeamentos, combinam-se o estudo da forma de organização informacional e os estudos de módulos e de outras formas de organização (GROBET, 2000, ROULET; FILLIETTAZ; GROBET, 2001).

Neste trabalho, procederemos à combinação da estrutura informacional e da estrutura hierárquica, que resulta do estudo do módulo hierárquico. A combinação das estruturas informacional e hierárquica permite descrever a hierarquia existente entre informações principais e subordinadas, fornecendo evidências a respeito do grau de acessibilidade, na memória discursiva, das informações que funcionam como ponto de ancoragem (os tópicos) e, consequentemente, do grau de importância que o locutor atribui a essas informações.

Em linhas gerais, o módulo hierárquico é o responsável por definir as categorias e as regras que permitem descrever as estruturas hierárquicas de um texto. Nesse módulo, considera-se que "toda intervenção linguageira (cumprimento, pedido, asserção, etc) constitui uma PROPOSIÇÃO, que desencadeia um processo de negociação entre os 
interactantes" (ROULET; FILLIETAZ; GROBET, 2001, p. 57). Assim, toda interação verbal caracteriza-se por um processo de negociação em que os agentes apresentam proposições, reagem a elas e as ratificam. Nesse sentido, toda unidade textual corresponde a uma das fases de um processo de negociação específico (proposição, reação e ratificação), e é

Gustavo

Ximenes Cunha

Rafael Vinícius

de Carvalho

Picinin esse processo que as estruturas geradas no módulo hierárquico reconstroem. Com a estrutura hierárquica, é possível visualizar as hierarquias e as relações que os constituintes do texto - trocas, intervenções e atos - estabelecem entre si (CUNHA, 2013).

Por motivo de espaço, analisaremos apenas a forma de organização tópica do fragmento da cartilha da ANATEL estudado no item anterior e formado pelos atos (05-17). A figura 4 resulta da combinação ou acoplagem da estrutura informacional do fragmento (quadro 1) e de sua estrutura hierárquica ${ }^{8}$.

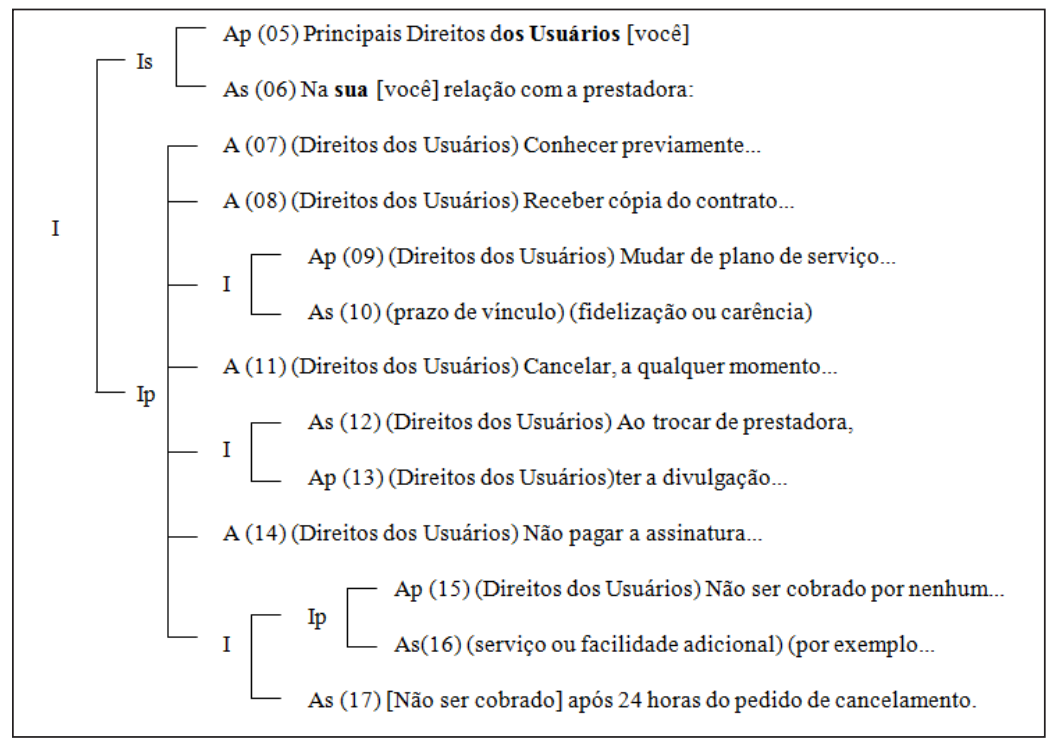

Figura 4 - Acoplagem das estruturas hierárquica e informacional

Como exposto na estrutura, o fragmento da cartilha compõe-se basicamente da justaposição de constituintes textuais que expressam informações sobre os direitos dos usuários. No que se refere à hierarquia dos constituintes textuais, os atos (05-06) formam uma intervenção que,

8 Do ponto de vista hierárquico, a estrutura apresenta estas informações: ato (A), intervenção (I), principal (p), subordinado (s). 
por indicar o tópico (Direitos dos usuários) das informações expressas na intervenção formada pelos atos (07-17), é subordinada em relação a esta. Já essa Ip (07-17) é formada por atos e intervenções coordenados que expressam os direitos dos usuários de telefonia fixa. 0 efeito de justaposição de informações é decorrente exatamente da coordenação de constituintes textuais. Do ponto de vista informacional, os atos (0506) ativam a informação Direitos dos usuários, que, uma vez estocada na memória discursiva dos interlocutores, funciona como tópico da maior parte dos atos do trecho em análise.

A combinação das estruturas informacional e hierárquica traz explicações para fenômenos apenas constatados na análise informacional. Como vimos, a maior parte dos atos não possui traços tópicos, isto é, expressões que indiquem o tópico a que um ato se liga. Conforme A negociação de faces, territóriose lugares em uma perspectiva interacionista da análise do discurso Grobet (2000), quanto mais acessível um tópico encontra-se na memória discursiva, menor a necessidade de marcas sinalizando o tópico. $\mathrm{Na}$ cartilha, a ativação de Direitos dos usuários logo no início do trecho deixa essa informação bastante acessível na memória discursiva dos interlocutores e, portanto, torna desnecessária sua retomada por expressões anafóricas ao longo do trecho.

Também vimos que, no fragmento, há atos que se ligam aos tópicos por encadeamento à distância. De modo geral, informações ativadas em atos mais distantes constituem informações menos acessíveis na memória discursiva. Sendo assim, quando uma informação desse tipo constitui tópico de um ato, o produtor do discurso costuma usar expressões anafóricas remetendo ao tópico, para auxiliar o leitor em seu trabalho de recuperar esse tópico pouco acessível (GROBET, 2000, ROULET; FILLIETTAZ; GROBET, 2001). Porém, na cartilha, quando há encadeamento à distância, o tópico é facilmente inferível ou recuperável, e o locutor não emprega traços tópicos. Uma explicação para essas propriedades da cadeia referencial da cartilha está na estrutura hierárquica do trecho. Como vimos, a ativação de Direitos dos usuários logo no início do trecho e em um ato principal, o ato (05), faz com que o grau de acessibilidade dessa informação seja elevado e dispense traços tópicos, mesmo quando o encadeamento se dá à distância.

No próximo item, estudaremos a forma de organização estratégica da cartilha da ANATEL, combinando o estudo do módulo referencial e o estudo realizado neste item e no anterior sobre as formas de organização informacional e tópica. 


\section{Análise da forma de organização estratégica da cartilha}

Nesta etapa final do trabalho, em que se estuda a forma de organização estratégica da cartilha, o objetivo é compreender o papel que, nessa cartilha, a cadeia referencial exerce na negociação de faces, territórios e lugares entre a ANATEL e os leitores.

Gustavo

Ximenes Cunha

Rafael Vinícius de Carvalho

Picinin

No modelo modular, a forma de organização estratégica estuda o modo como os agentes, numa dada interação, coordenam as relações de faces, territórios e lugares. A finalidade é explicar os comportamentos dos agentes em termos de estratégias discursivas (BURGER, 1995). No estudo da gestão das relações de faces e territórios, combinam-se informações acerca dessas noções de face e território, componentes do quadro acional, com informações de outros módulos e formas de organização, para verificar, em perspectiva semelhante à de Brown e Levinson (1987), como os agentes fazem dos recursos linguageiros estratégias para reduzir as ameaças às suas faces e aos seus territórios. Por sua vez, o estudo das relações de lugares descreve o papel da linguagem no estabelecimento da relação vertical ou de dominância/poder entre os interactantes, durante o desenvolvimento da interação (ROULET, 1999, ROULET; FILLIETTAZ; GROBET, 2001).

$\mathrm{Na}$ cartilha da ANATEL, a gestão de faces, territórios e lugares entre a agência e o usuário dos serviços de telefonia fixa é complexa. Tendo em vista seu status de agência reguladora do Estado, a ANATEL tem legitimidade para atacar a face do leitor, reservando a ele o lugar de interlocutor sem direito à fala (a interação é monologal e sem a representação de trocas fictícias com o leitor), e para invadir seu território, prescrevendo seus direitos e, consequentemente, limitando sua liberdade futura de ação. Mas, porque as agências foram criadas com a finalidade de fiscalizar e regular a prestação de serviços ao usuário/ consumidor, esses ataques são contrabalançados pela suposição de que uma agência reguladora, como a ANATEL, age em benefício do consumidor, ao informar seus direitos e as obrigações das empresas privadas prestadoras de serviços de telefonia.

A atuação ambígua da agência, que ataca a face do leitor para supostamente proteger seus direitos em relação às empresas, é a responsável pela maneira como o texto da cartilha é estruturado. Ao listar em intervenções coordenadas os direitos do leitor e as obrigações das empresas, a agência cria uma relação de lugares desigual entre uma instância de produção (a ANATEL) que detém poder, conhecimento e legi- 
timidade para atribuir direitos e deveres e uma instância de recepção (o leitor da cartilha) que, por necessitar de informações e orientações sobre direitos conexos à prestação de serviços de telefonia, detém menos poder e conhecimento. Porém, a desigualdade dessa relação de lugares não é agressiva para a face e o território do leitor, uma vez que, como exposto no estudo do módulo referencial e da forma de organização informacional, o leitor a quem a ANATEL se dirige não se identifica com o cidadão cujos direitos e deveres estão prescritos na Constituição ${ }^{9}$, mas com o usuário ou o consumidor cujos direitos e deveres estão prescritos em contratos com empresas privadas.

Ao proceder dessa forma, a ANATEL, reivindicando a imagem de instância fiscalizadora e reguladora, reitera o papel meramente administrativo do Estado e constribui para legitimar a Reforma em cujo âm-

A negociação

de faces, territóriose lugares em uma perspectiva interacionista da análise do discurso bito foi criada, uma Reforma que, como vimos no estudo da representação conceitual da cartilha (Figura 1), se pautou pelo enxugamento da máquina estatal, via diferentes mecanismos (privatização, terceirização e publicização), e pelo fortalecimento do mercado. Nessa perspectiva, a ANATEL figura-se como coadjuvante na proteção do consumidor, já que ao Estado não cabe desempenhar a função de prestador direto de serviços públicos, como o de telefonia fixa, mas sim atuar como mero regulador das práticas postas no mercado e da relação entre empresas e usuários/consumidores.

Em outros termos, compor uma cartilha por meio da listagem de atos que remetem basicamente e de forma constante aos tópicos direitos do consumidor/usuário e deveres de empresas privadas constitui uma estratégia discursiva condizente com uma instituição, a agência, criada por uma Reforma a que subjaz o ideário do Estado Mínimo e do livre mercado. Com isso, derrota-se a noção de Estado interventor e assegurador de direitos constitucionais do cidadão, fortalecendo-se, de toda sorte, a consolidação da Reforma do Estado e das políticas administrativas descentralizadoras (DASSO Jr., 2006).

Propondo cartilhas como a que analisamos neste trabalho, a ANATEL, em cumprimento de seu dever legal regulador e informativo, faz presumir equilíbrio das relações contratuais firmadas entre usuários e prestadoras de serviços, contribuindo para aumentar a aceitabi-

9 Na definição de Bourdieu (2014, p. 455-456), o cidadão é "essa entidade jurídica que existe como alguém que mantém relações de direito e de dever com o Estado" e "é aquele que é reconhecido com tal pela Constituição". 
lidade, perante os leitores de discursos institucionais, do projeto descentralizador do Estado e de enxugamento da máquina pública, como estratégia administrativa. Com o estudo aqui desenvolvido, verifica-se que à visada informativa ou instrucional da cartilha sobrepõe-se uma visada de convencimento do leitor e de naturalização de determinados Gustavo discursos acerca da administração pública/privada e de interesses de

Ximenes Cunha

Rafael Vinícius de Carvalho

Picinin mercado. Verifica-se, dessa forma, que a construção da cadeia referencial em uma cartilha institucional pode exercer papel de primeira importância na negociação de faces, territórios e lugares.

\section{Considerações finais}

Este trabalho apresentou o Modelo de Análise Modular do Discurso, direcionando suas contribuições à análise de cartilha institucional da Agência Nacional de Telecomunicações, a ANATEL. Como exposto na introdução, nosso intuito foi, além de oferecer uma apresentação do modelo modular, evidenciar que os instrumentos teóricos e metodológicos dessa abordagem permitem um estudo aprofundando não apenas da estruturação de discursos dialogais ou produzidos por interlocutores face a face, mas também de processos complexos de co-construção de sentidos e de negociação de faces, territórios e lugares verificáveis mesmo em gêneros monologais e escritos, como a cartilha institucional.

Com o percurso de análise proposto, analisou-se a cartilha da ANATEL, inicialmente, do ponto de vista do módulo referencial. Em seguida, procedeu-se ao estudo das formas de organização informacional e tópica. Por fim, os estudos precedentemente realizados foram combinados na análise da forma de organização estratégica da cartilha. Ao final do percurso, foi possível verificar o papel que a cadeia referencial da cartilha da ANATEL desempenha na gestão das relações de faces, territórios e lugares.

Enquanto estratégia discursiva, a maneira como na cartilha as informações são ativadas e reativadas pode conduzir o leitor à crença de que a ANATEL implementa medidas eficazes de proteção dos direitos dos consumidores, especialmente aqueles relacionados à prestação privada dos serviços de telefonia fixa, cuja natureza pública não se desnaturou após o processo de privatização desses serviços. Constatou-se, portanto, mediante o percurso de análise adotado, que, na cartilha institucional, a justaposição de direitos do consumidor e de deveres de empresas pode ter como efeito diluir a tensão causada com o processo privatizador de empresas públicas e, ao mesmo tempo, difundir a noção 
de atuação efetiva do Estado em defesa do cidadão, que passa, na nova conjuntura, a ser entendido como usuário ou consumidor dos produtos oferecidos por empresas de telefonia em concorrência.

Com base nos instrumentos teóricos e metodológicos do modelo modular, a análise desenvolvida por meio da articulação de aspectos linguísticos, textuais e situacionais revela uma relação bastante estreita entre o contexto político e histórico de criação das agências e os gêneros do discurso de que as agências se valem para exercer seu papel. Por isso, o estudo da cartilha da ANATEL possibilitou mostrar a forte interação entre aspectos ligados à seleção de recursos linguísticos e textuais e aspectos de ordem situacional.

A negociação

de faces, territóriose lugares em uma perspectiva interacionista da análise do discurso

\section{REFERÊNCIAS}

BARROSO, Luis Roberto. Agências reguladoras. Constituição, transformações do estado e legitimidade democrática. Revista de Direito Administrativo, Rio de Janeiro/RJ, n. 229, p 285-311, 2002.

BENTES, Anna Christina; REZENDE, Renato Cabral. Texto: conceitos, questões e fronteiras [com] textuais. In: SIGNORINI, Inês. (org). [Re] discutir texto, gênero e discurso. São Paulo: Parábola Editorial, 2008, p. 19-46.

BRESSER-PEREIRA, Luiz Carlos. A Reforma do estado dos anos 90: lógica e mecanismos de controle. (Cadernos MARE da reforma do estado, v. 1.) Brasília: Ministério da Administração Federal e Reforma do Estado, 1997.

BROWN, Penelope; LEVINSON, Stephen. Politeness: some universals in language use. Cambridge: Cambridge University Press, 1987.

BOURDIEU, Pierre. Sobre o Estado. São Paulo: Companhia das Letras, 2014.

BURGER, Marcel. L'identité négociée: "rapports de place(s)" dans un entretien télédiffusé. Cahiers de linguistique française, Genebra, n 17, p. 09-33, 1995. 
CUNHA, Gustavo Ximenes. O sequenciamento de textos como estratégia discursiva: uma abordagem modular. 250f. Dissertação (Mestrado em Linguística). Faculdade de Letras, Universidade Federal de Minas Gerais, Belo Horizonte-MG, 2008.

Gustavo

Ximenes Cunha

Rafael Vinícius de Carvalho

Picinin . A construção da narrativa em reportagens. 601f. Tese (Doutorado em Linguística). Faculdade de Letras, Universidade Federal de Minas Gerais. Belo Horizonte-MG, 2013.

Para entender o funcionamento do discurso: uma abordagem modular da complexidade discursiva. Curitiba: Appris, 2014.

Análise de uma cartilha institucional em uma abordagem modular da complexidade do discurso. Revista do GEL, Campinas/ SP, n. 13, p. 31-55, 2016.

A construção de imagens de si no discurso organizacional. In: TOMAZI, Micheline Mattedi; ROCHA, Lúcia Helena Peyroton da; POMPEU, Júlio César. (Orgs.). Estudos discursivos em diferentes perspectivas: mídia, sociedade e direito. São Paulo: Terracota Editora, 2016a, p. 111-126.

CUNHA, Gustavo Ximenes; OLIVEIRA, Ana Larissa Adorno Marciotto; PICININ, Rafael Vinicius de Carvalho. A nominalização deverbal em cartilhas de agências reguladoras do Estado: de como a gramática produz efeitos de autoridade e não-negociação. ACTA, Maringá, A nominalização deverbal em cartilhas de agências reguladoras do Estado: de como a gramática produz efeitos de autoridade e não-negociação. Acta Scientiarum. Language and Culture (Online) , 2017.

DASSO JR., Aragon Érico. Reforma do Estado com participação cidadã?: déficit democrático das agências reguladoras brasileiras. Tese (Doutorado em Direito). Centro de Ciências Jurídicas, Universidade Federal de Santa Catarina, Florianópolis-SC, 2006.

DUCROT, Oswald. 0 dizer e o dito. Traduzido por Eduardo Guimarães. Campinas: Pontes, 1987. 
FILLIETTAZ, Laurent. Actions, activités et discours. 2000. 403f. Tese (Doutorado em Linguística). Faculdade de Letras, Universidade de Genebra, Genebra, 2000.

GOFFMAN, Erving. La mise em scène de la vie quotidienne: les relations em public. v. 2. Paris: Les éditions de minuit, 1973.

A negociação

de faces, territóriose lugares em uma Ritual de interação: ensaios sobre o comportamento face a perspectiva interacionista da análise do discurso

GROBET, Anne. L'identification des topiques dans les dialogues. 2000. 513f. Tese (Doutorado em Linguística). Faculdade de Letras, Universidade de Genebra, Genebra, 2000.

KERBRAT-ORECCHIONI, Catherine. Les interactions verbales. v. 1. Paris: Colin, 1992.

KOCH, Ingedore Grunfeld Villaça. A inter-ação pela linguagem. São Paulo: Contexto, 1997.

MARINHO, Janice Helena Chaves. Uma abordagem modular e interacionista da organização do discurso. Revista da Anpoll, São Paulo/ SP, n. 16, p. 75-100, 2004,.

MORATO, Edwiges. O interacionismo no campo linguístico. In: MUSSALIM, Fernanda; BENTES, Anna Christina. Introdução à Linguística: fundamentos epistemológicos. São Paulo: Cortez, 2004, p. 311-352.

ROULET, Eddy. La description de l'organisation du discours. Paris: Didier, 1999.

ROULET, Eddy; FILLIETTAZ, Laurent; GROBET, Anne. Un modèle et un instrument d'analyse de l'organisation du discours. Berne: Lang, 2001.

RUFINO, Janaína de Assis. As mulheres de Chico Buarque: análise da complexidade discursiva de canções produzidas no período da ditadura militar. Dissertação (Mestrado em Linguística). Faculdade de Letras, Universidade Federal de Minas Gerais, Belo Horizonte-MG, 2006. 
VION, Robert. La communication verbale: analyse des interactions. Paris: Hachette, 1992.

Gustavo

Ximenes Cunha

Rafael Vinícius

de Carvalho

Picinin
Recebido em 06 de março de 2017.

Aceito em 05 de maio de 2017.

40 